\title{
Mobile Learning: Visualization Tools of Data Structures Course to Support Learning Students
}

\author{
Edy Budiman, Nataniel Dengen, Ummul Hairah \\ Dept. of computer science and information technology \\ Universitas Mulawarman \\ Samarinda, Indonesia \\ edybudiman.unmul@gmail.com,
}

\begin{abstract}
Mobile learning course of data structure, it cannot only be used as auxiliaries of learning, but also an independent learning mode. The various approaches theory of research and development, software design, and methods we use into built of media. The main objective is the construction of educational software adapted to learning. First and foremost, it is essential to have in mind that our application is designed for two very specific public; on the one side the lectures, who will use it as a teaching tool, and another side the students, for learning purposes. This research has created a mobile learning application for courses of data structures, the learning material is presented visually according curriculum-syllabus and learning outcomes of data structures. This application as one a learning media to support students who can be used all the time (long life learning).
\end{abstract}

Keywords-Mobile Learning, Data-Structures, Course, Students, Visualization.

\section{INTRODUCTION}

In Computing Curricula, the curriculum guidelines for undergraduate Degree Programs in Computer Science [1] and Computer Engineering [2] study of fundamental concepts, terms of data structures and the skills, necessary for their use in modeling real-world tasks, are a part of the subject matter of the Fundamental Data Structures and Algorithms (knowledge area Software Development Fundamentals and Algorithms and Complexity) courses [3]. The study of data structures and algorithms provides insight into the intrinsic nature of the problem as well as possible solution techniques independent from programming language, programming paradigm, computer hardware, or any other implementative aspect [1].

Reference [1], explains that data structure is knowledge area defining the central concepts and skills required to design, implement, and analyze algorithms for solving problems. Algorithms are essential in all the advanced areas of computer science: artificial intelligence, databases, distributed computing, graphics, networking, operating systems, programming languages, security, and so on. Algorithms that have specific utilities in each of these are listed in the relevant knowledge areas. However, many students find those difficult, less interest, passive, lazy to learn them. This is because this material requires abstract thinking [4], and learning of data structures is complex issue for many students [5-8], and complexity is defined as a problem that can have several solutions. Data structure is an important subject for 2nd year students at University of Mulawarman (UNMUL), but it is difficult to work with them due to their abstract nature [9].

Failure into learning [10] and understand the courses leads to significantly lower student learning outcomes at the final semester [11]. Solution to understand complex data structures or algorithm is to see them in action [12]. The present work a new tool for develop, and implement mobile learning of data structures for supporting on students' learning. This is especially useful for students and lecturers in computer science in UNMUL.

Mobile learning tools developed to make a learning of data structures course is easy and interesting. While using these tools, the tool would allow students to see the workings of common operations in form of changes that take place to the corresponding data structure. Moreover, this tool would provide a simple language, they understand how to the material course work, and how the operations are executed. It would be very helpful if there were a visualization tool of data structures for students to experiment.

This study is intended to create such an exploration environment, in which students can learn through experimentation. The tool can be used as an effective supplement to the traditional classroom education and textbooks for data structures courses. The application package presented in this paper has the following functionality: (1) Provides a visual learning materials based on the curriculum syllabus and learning outcomes of data structures course, (2) The materials of teaching include of theory and basic concepts, the complexity of the algorithm, an online reference list, the simple code of material, running the program output is presented in a visualization and animation, and (3) Provides simple animation for user-defined algorithms and common operations, such as inserting an element and deleting an element from the specified data structures.

\section{RELATED WORK}

\section{A. A Review of Research on Mobile Learning}

Mobile technologies, such as smartphones, tablets, and laptops, as well as online applications, networking, internet and 
tools [13-15], became an integral part of the lives of most teachers and students in East Borneo. These devices have transformed the way that people communicate, search for information and work. The challenge for the educators and researchers was to explore how mobile technologies might be used to support learning [16-17]. In 2015, Indonesian mobile cellular users, especially in major urban centers, had firmly adopted mobile cellular services in all walks of life including e-education [18]. Mobile devices have become an attractive learning tools for education. Existing research has mainly focused on the value of mobile learning for students [19] and teachers [20].

Mobile learning research on the subject has been done by the data structures in [8] with study reports on various papers on how researchers - computer scientists have gone about to tackle the problems faced by students in learning data structures and various approaches that are taken to make data structures learning more fun and effective. This literature review includes various tools, technologies, advantages of using these technologies and suggestions on the techniques that can be combined for effective learning of data structures.

\section{RESEARCH DESIGN AND METHODOLOGY}

This study requiring to design and development of mobile learning tool for data structure courses intended for an Undergraduate Degree of informatics engineering class, the tool was designed with the initial objective of creating an instructional assist for the students of the Informatics Engineering course at UNMUL. The ultimate goal is to develop and implement of the mobile learning based on android as a learning resource to support in an effort to increase student interest and creativity in learning of data structure courses.

\section{A. Research Methodology}

Research methodology in this paper uses of approaches educational Research and Development (R\&D), to develop and validate of mobile learning. The steps of this process are referred to as the R \& D cycle, which consists of studying research findings pertinent to the product to be developed, developing the product based on the finding, field testing it in the setting where it will be used eventually, and revising it to correct the deficiencies found in the field testing stage. indicate that product meets its behaviorally defined objectives [21].

\section{B. Design Software for Mobile Learning}

The Software Development Life Cycle (SDLC) is a domain of competency used in systems engineering, information systems and software engineering to describe a process for planning, creating, testing, and deploying an information system [22]. The software development models used in building mobile learning of data structures courses is VShaped Model [23]. The V-Shaped SDLC Model is an extension of the waterfall model that introduces the added responsibility of defining the criteria for system testingevaluation during each stage of the system design.

\section{Architecture System for Mobile Learning}

There are 3 key elements that must be provided in the development of mobile learning system, in "Fig. 2" is the availability of network infrastructures, smartphone devices, and application software.

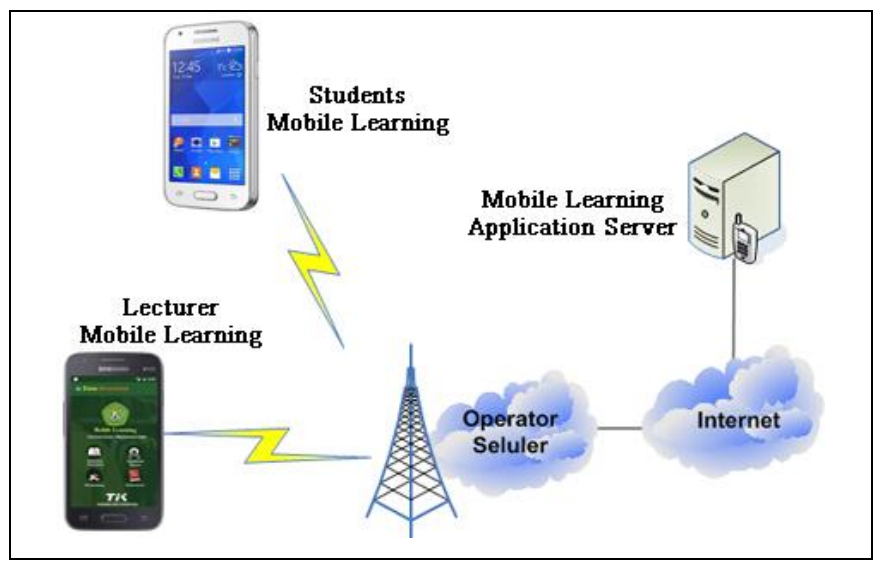

Fig. 1. Structure of mobile learning system

1) Network infrastructures: in Samarinda city, the availability of mobile networks has researchers did a study of quality of service mobile network in Samarinda [14], [24].

2) Devices smartphone: Generally, every student has a smartphone that can to support mobile learning applications,

3) Application software: for the availability of software applications, we design and develop of mobile learning course for the data structure that can support learning 2nd year students for undergraduate Degree Programs at UNMUL.

Framework adaptation mobile learning environment, the system architecture is designed based on the $5 \mathrm{R}$ adaptation from framework [25], [26]. The adaptation mechanism and process shown in "Fig. 2". The platform is based on the 5R input ontology that ensures all the learning contents developed to be used by the $5 \mathrm{R}$ adaptation mechanism.

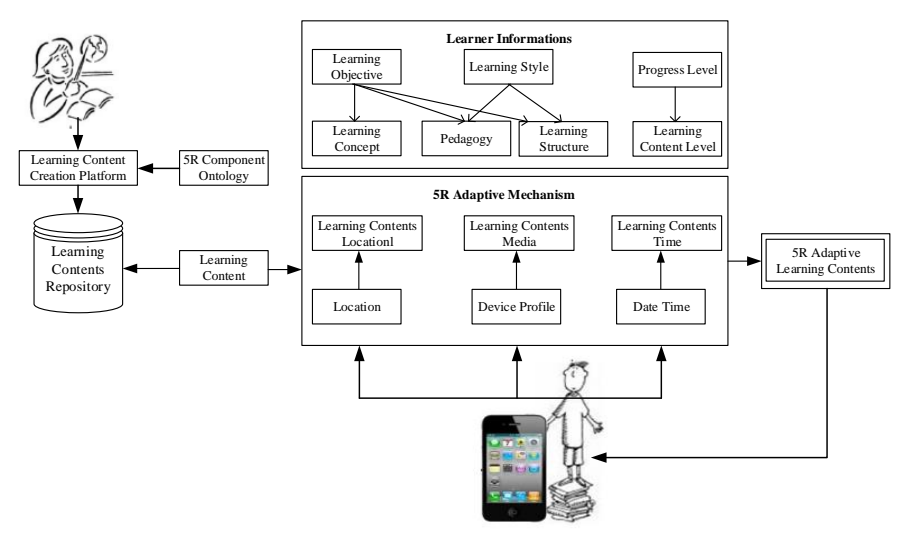

Fig. 2. The 5R adaptation mobile learning system architecture

\section{Software Analysis and Design}

The design and development of mobile application determined as hard procedure regarding to technical phases 
such as software programming, interface designing and familiarity with smart phone hardware. The analysis and design software used in the development of this system using object-oriented modeling Unified Modeling Language (UML) for object visualization [27]

\section{RESULTS}

Implementation is the realization of an application, In the implementation phase, the application of mobile learning course data structure is run to see how the system was built and worked in practice.

\section{A. Implementation: Role assignments of user}

In "Fig. 3", who explained the role assignment mobile learning, for student, presented the menu option include information learning outcomes for a course and syllabus, the student can do a searching the material topic include references.

The main activities student in the mobile learning is the access to the material, in this menu, students can do learning materials of data structures course, learning materials that contains; basic theory, weaknesses and strengths of materials, complexity, steps to resolve the algorithms, examples source code program, and visualization of running a program that can set its value by the user. For the lecturer, perform activities of material management, reference, information that will be presented to students.

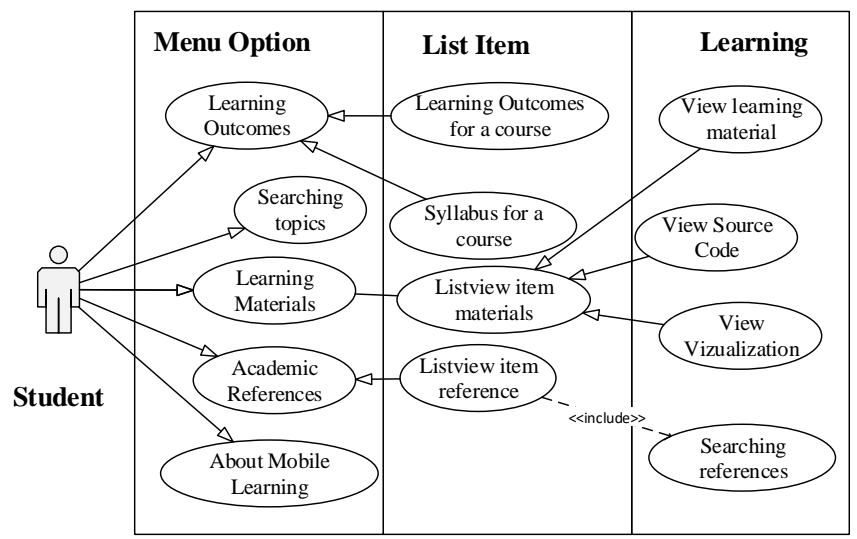

Fig. 3. Use case diagram for students

In general, hierarchical information about the content of the learning material on the mobile learning can be seen in the mind map diagram, see in "Fig. 4".

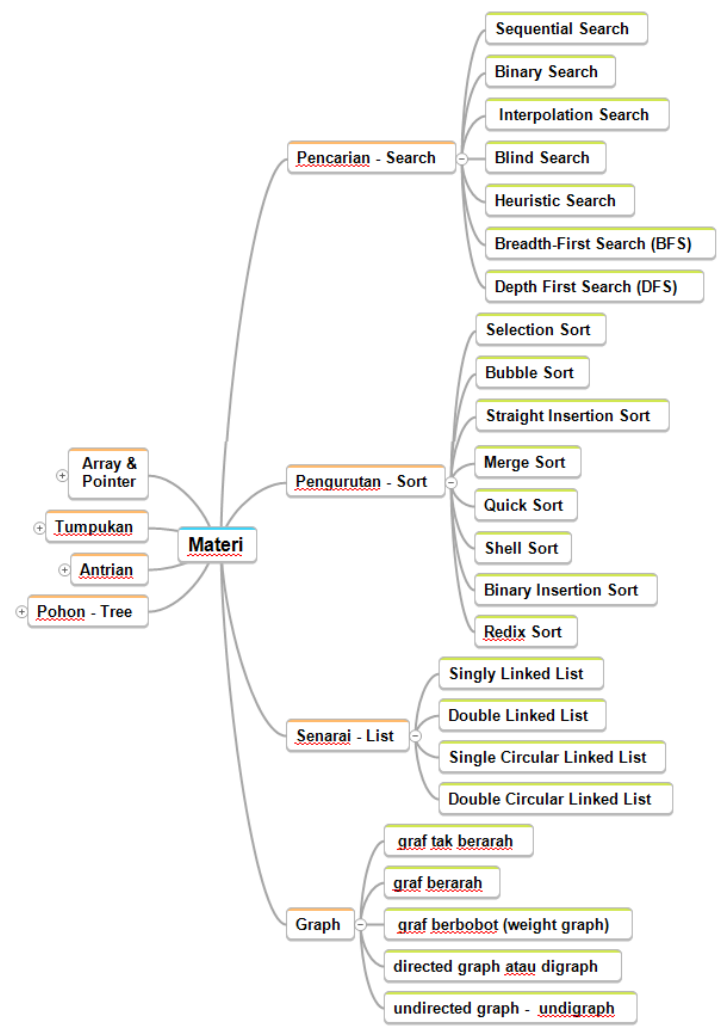

Fig. 4. Mind-map diagram material learning of data structures course

\section{B. Implementation: User interface module}

The real mobile application which can be installed on Android system was one of the ultimate production of this study. It is conceived as a learning system with a base on mobile android, utilizing smartphone a student's for learning, and organizing the students' learning process anytime and anywhere. The main user interface can be seen in "Fig. 5(a)", showing a menu of options provided, such as;

1) Learning outcomes: data structures in accordance with curricula-syllabus, and learning outcomes of the course see in "Fig. 5(b)".

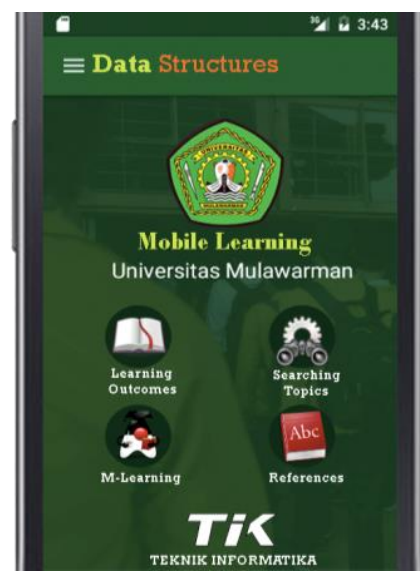

(a)

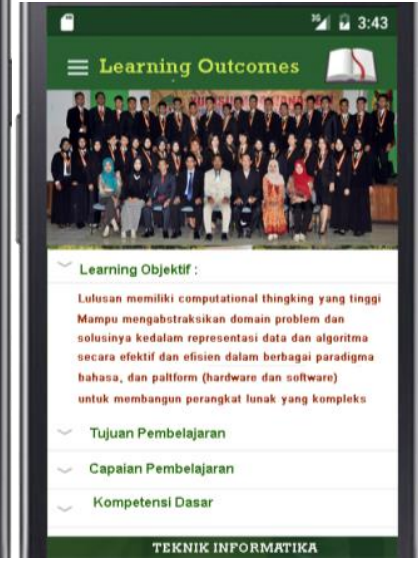

(b)
Fig. 5. User interface main module and learning outcomes 
2) Searching material: can do a quick search keyword order by name or title in the database system, the references, contains reference materials used in teaching this course. can be accessed online at the website address link source and the reference list of books related material. See in "Fig. 6".

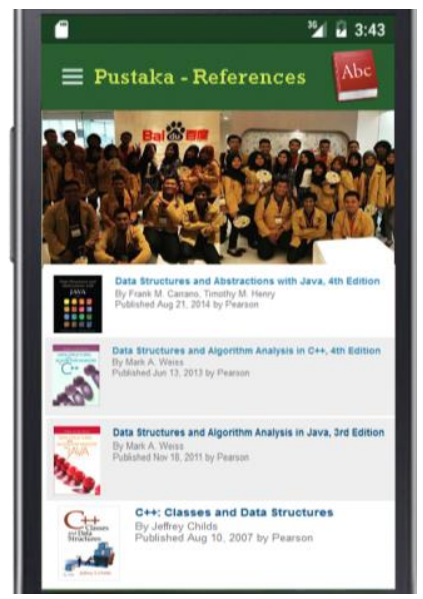

Fig. 6. User interface module references

3) M-Learning, contain instructional material taught during the semester, which includes material arrays, pointers, list, stack, queue, tree, sort, search, and graph the kinds and types of each packaged in the form of learning theory, source code, and animations interactive visualizations. See "Fig. 7".
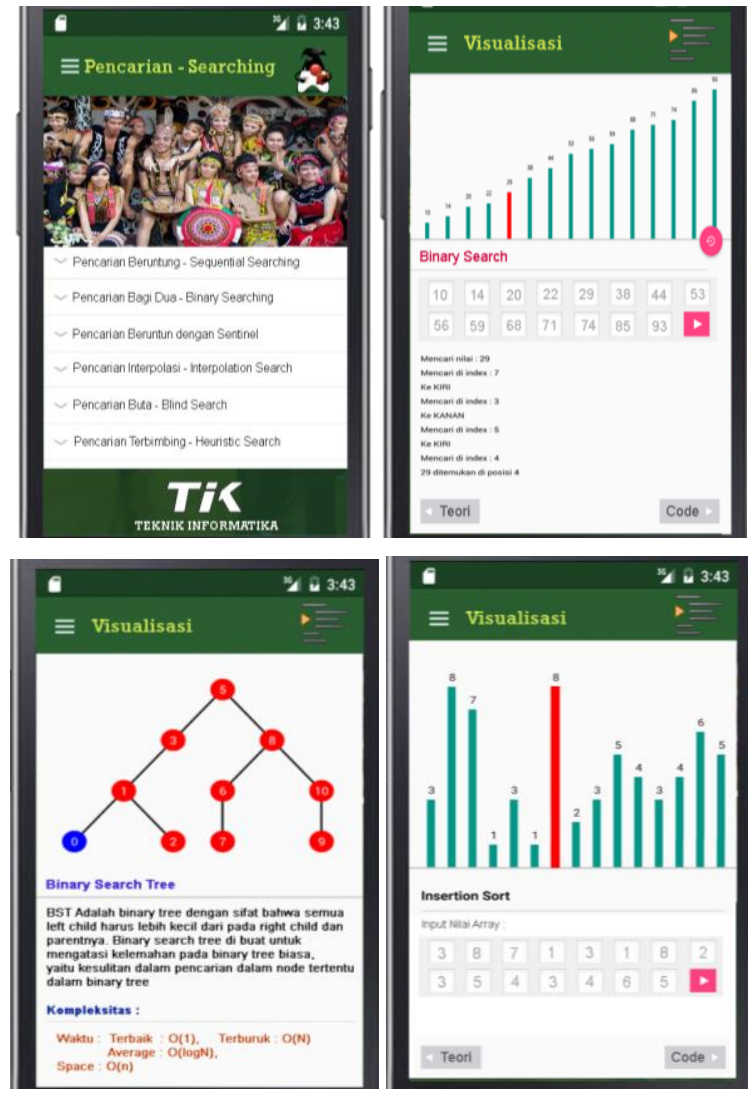

Fig. 7. User interface module m-learning

\section{DISCUSSION AND CONCLUSION}

From the teaching work in these years, we deeply feel that the data structures course is so important for students in the study of computer science and technology. How to turn this course from a difficult and boring course into an interesting course is becoming an urgent issues. Student teaching experience from previous years into our evaluation that this year is much better.

The student difficulties in learning this course encourages teams to develop learning tools that utilize the smartphone device that students have for learning media. A mobile learning media to subject the data structure with the theoretical material in accordance with the course syllabus. To be easily understood by the students, presenting the material is accompanied by examples of the application in a simple case study, with source code and running code in the form of animated visualizations that move output and attractive. Development and implementation of mobile learning data structures course, it can not only be used as auxiliaries of learning, but also an independent learning mode.

The media has been used by 2nd-year students for undergraduate Degree Programs informatics UNMUL in this semester and is still used as a supporting media lecturer's in teaching. The final evaluation of the use of mobile learning media in lectures this semester, we will do with analyzing the media's impact on student learning outcomes are achieved, and in the next academic year we will continue to develop these tools, additional material, and examples of exercises for each material. otherwise it is not only limited in platform android but also for other mobile platform.

\section{REFERENCES}

[1] ACM and IEEE, Computer Science Curricula 2013: Curriculum Guidelines for Undergraduate Degree Programs in Computer Science, The Joint Task Force on Computing Curricula, Association for Computing Machinery (ACM), IEEE Computer Society, Dec, 2013.

[2] ACM and IEEE, Computer Engineering Curricula 2016: CE2016 Curriculum Guidelines for Undergraduate Degree Programs in Computer Engineering: A Report in the Computing Curricula Series, Joint Task Force on Computer Engineering Curricula Association for Computing Machinery (ACM) - IEEE Computer Society, Dec, 2016.

[3] V. Dyankova, S. Kapralov, M. Yankov, and Y. Ismailov, "A Web-based educational system for learning data structures", International Journal of Technical Research and Applications, vol. 2(5), 2014, pp. 126-132.

[4] T. Chen, and T. Sobh, "A tool for data structure visualization and userdefined algorithm animation", In Frontiers in Education Conference, 2001. 31st Annual IEEE, vol. 1, pp. TID-2, 2001.

[5] J. Hartmanis, and J. E. Hopcroft, "An overview of the theory of computational complexity", Journal of the ACM (JACM), vol. 18(3), 1971, pp. 444-475.

[6] N. M. Oliet, Y.O. Mallén, J. A. López, Estructuras de Datos y Métodos Algorítmicos: Ejercicios Resueltos, Pearson Educación, 2004.

[7] E. L. Muños Andrade, C. A. Arevalo Mercado, J. M. Gomez Reynoso, "Learning Data Structures Using Multimedia-Interactive Systems, Communications of the IIMA, vol 8, no. 3, 2014, p. 3.

[8] S. Patel, A Literature Review On Tools For Learning Data Structures, University of Cape Town, 2014.

[9] L. Alzubaidi, A. El Hassan, "Data Structures Learning-A Visually Assisted Approach", In Proceedings of the International Conference on Computer Graphics and Virtual Reality (CGVR) Jan, 2013, p. 37. 
[10] J. A. Crowe, T. Silva, and R. Ceresola, "The effect of peer review on student learning outcomes in a research methods course", Teaching Sociology, vol. 43. No. 3, 2015, pp. 201-213.

[11] E. Informatics, "Evaluation of Learning Odd semester - Academic Year 2015/2016 Students of Informatics Engineering, University Mulawarman, Report, 2016.

[12] K. Musumbu, Algorithms Visualization Tool for Students and Lectures in Computer Science, arXiv preprint arXiv, p.1403.4423, 2014.

[13] ATSI, Summary Report: Building a Digital Indonesia a Snapshot of the Indonesian Telecommunication Industry 2015, ATSI, Jakarta, 2016.

[14] E. Budiman and O. Wicaksono, "Measuring quality of service for mobile internet services," in 2016 2nd International Conference on Science in Information Technology - ICSITech 2016: Information Science for Green Society and Environment, pp. 300-305, 2016. DOI: 10.1109/ICSITech.2016.7852652

[15] W. H. Wu, Y. C. J. Wu, C. Y. Chen, H. Y. Kao, C. H. Lin, and S. H. Huang, "Review of trends from mobile learning studies: A metaanalysis," Computers \& Education, vol. 59, no. 2, 2012, pp. 817-827.

[16] D. Frohberg, C. Göth, and G. Schwabe, "Mobile learning projects-a critical analysis of the state of the art", Journal of computer assisted learning, vol. 25, no. 4, 2009, pp. 307-331.

[17] A. S. Drigas, M. A. Pappas, A review of mobile learning applications for mathematics, Learning 3, 2015, p. 6.

[18] P. Marius and S. Anggoro, Profil Pengguna Internet Indonesia 2014, APJII, Jakarta, 2015.

[19] M. Alqahtani, and H. Mohammad, "Mobile applications' impact on student performance and satisfaction," in Turkish Online Journal of Educational Technology-TOJET, vol. 14, no. 4, 2015, pp. 102-112.
[20] E. Baran, "A review of research on mobile learning in teacher education," Educational Technology \& Society, vol. 17. no. 4, 2014, pp. 17-32.

[21] W. R. Borg and M. D. Gall, Educational Research: An Introduction, New York: Longman, 1983.

[22] P. Isaias, and T. Issa, Information System Development Life Cycle Models, In High Level Models and Methodologies for Information Systems, Springer New York, 2015, pp. 21-24.

[23] K. Ali, "A Study of software development life cycle process models," in International Journal of Advanced Research in Computer Science, vol. 8. no 1, jan, 2017.

[24] E. Budiman and U. Hairah, "End-to-End QoS tool development and performance analysis for network mobile," in International Journal of Scientific Research in Science, Engineering and Technology (IJSRSET), vol. 3:2, pp.128-135, March-April 2017.

URL: http://ijssset.com/IJSRSET173242

[25] W. Chang, and Q. Tan, "Augmented reality system design and scenario study for location-based adaptive mobile learning," In Computational Science and Engineering (CSE), 2010 IEEE 13th International Conference on, Dec, 2010, pp. 20-27.

[26] Q. Tan, X. Zhang, and R. M. Kinshuk, "The 5R adaptation framework for location-based mobile learning systems. In 10th World Conference on Mobile and Contextual Learning, 2011, pp. 18-21.

[27] A. Dennis, B. H. Wixom, D. Tegarden, "Systems Analysis And Design: An Object-Oriented Approach with UML," John Wiley \& Sons, Mar, 2015. 